\title{
A visita médica domiciliar como espaço para interação e comunicação em Florianópolis, SC*
}

Renata Borges ${ }^{1}$

Ana Flávia Pires Lucas D`Oliveira²

BORGES, R.; D'OLIVEIRA, A.F.P.L. The medical home visit as a space for interaction and communication in Florianópolis - Santa Catarina. Interface - Comunic., Saude, Educ., v.15, n.37, p.461-72, abr./jun. 2011.

This paper discusses the medical home visit based on research carried out in the municipality of Florianópolis, state of Santa Catarina (Southern Brazil), in the context of the Family Health Strategy. The main objective was to understand how the home visit impacts on medical practice, regarding changes in the quality of the interaction between the professional, the patient and his family. Qualitative methodology was adopted along with triangulation techniques, which combined interviews, participant observation and the reading of documents. It was noticed that the home visit encourages interaction by promoting communication oriented towards mutual understanding. Thus, the professional can strive to have technical efficiency (technical success) combined with the understanding and focus on projects of happiness of patients and family members (practical success).

Keywords: Medical home visit. Communication. Interaction. Family Health Strategy.
Este artigo discute a visita médica domiciliar, com base em pesquisa realizada no município de Florianópolis, Santa Catarina, tendo como cenário a Estratégia Saúde da Família. O objetivo principal foi compreender como a visita domiciliar impacta a prática médica, com relação a mudanças na qualidade da interação entre o profissional, o paciente e sua família. Adotou-se metodologia qualitativa, com triangulação de técnicas, combinando entrevistas, observação participante e leitura de documentos. Percebeu-se que a visita domiciliar estimula a interação, por favorecer uma comunicação voltada ao entendimento mútuo, facilitando ao profissional compor a busca da eficácia técnica (êxito técnico) com a compreensão e foco nos projetos de felicidade dos pacientes e familiares (sucesso prático).

Palavras-chave: Visita médica domiciliar. Comunicação. Interação. Estratégia saúde da família.

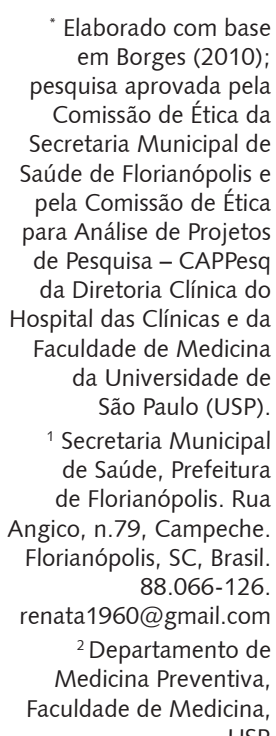

USP. 


\section{Introdução}

A Estratégia Saúde da Família propiciou o espaço e incentivo para que as visitas médicas pudessem realizar-se com maior frequência no Brasil. O Programa Nacional de Agentes Comunitários de Saúde, implantado em 1991 (denominado PACS, em 1992), evidenciou o trabalho do agente comunitário de saúde, realizando visitas domiciliares, incorporando o enfermeiro e, posteriormente, com o Programa Saúde da Família (1994), também o profissional médico (Viana, Dal Poz, 1998).

A visita domiciliar traz consigo um significado simbólico muito forte: ela é um espaço concedido pelo usuário em seu domićlio, diversamente do serviço de saúde, que é um espaço bem mais protegido para o profissional. Para o paciente e seus familiares em geral, a visita representa um cuidado especial, simbolizando um compromisso da equipe. Ela fortalece o vínculo entre o profissional, equipe e o usuário (Joyce, Pitman, 2008; Berg, 2006; Cunha, 2005; Bergeron et al., 1999; McWhinney, 1997).

Ainda que, muitas vezes, realizada de forma burocrática, e criticada em razão disso por alguns autores (Franco, Merhy, 2003), a visita domiciliar tem adquirido um papel de natureza estruturante no contexto da ESF (Peres, Dal Poz, Grande, 2006). Segundo estudo de Peres, Dal Poz e Grande (2006, p.212), isso ocorreria

diante do caráter relacional e intimista que a visita domiciliar proporciona aos profissionais e usuários, do expressivo número de dias atribuídos a visitas domiciliares realizadas pelos médicos e enfermeiros, bem como a centralidade que a visita ocupa no PSF.

Assim, na medida em que o profissional médico tem a oportunidade de acompanhar este usuário e sua família, a visita domiciliar (VD) pode tornar-se um espaço que propicia a interação e o diálogo, ultrapassando a questão técnica, exclusivamente (Albuquerque, Bosi, 2009; Peres, Dal Poz, Grande, 2006; McWhinney, 1997).

Para que esse processo ocorra, é preciso que o médico esteja presente e atuante na comunidade, sendo sua formação de tal modo que dê conta de contemplar os problemas de saúde mais prevalentes, relacionando-se com o paciente e sua família e tendo a abertura para aceitar opiniões e condutas, algumas vezes, diversas das que são prescritas pelos protocolos. Na ESF, a longitudinalidade está integrada à ideia de responsabilidade e vínculo, responsabilidade esta que é compartilhada entre profissionais e usuários, à medida que se (re)conhecem e podem estabelecer vínculos de confiança entre si (Takeda, 2006; McWhinney, 1997; Starfield, 1994).

É necessário, ainda, que definamos os conceitos de comunicação e interação, inseridos no contexto atual de uma medicina cada vez mais especializada e tecnológica (Schraiber, 2008, 1997, 1993; Dalmaso, 2000). Adotamos a abordagem habermasiana, na qual a comunicação não se refere à relação do sujeito isolado a algo no mundo, que pode ser representado e manipulado, mas à relação intersubjetiva que assumem sujeitos capazes de linguagem e de ação quando eles se entendem entre si sobre algo (no mundo). À medida que os participantes da comunicação buscam um acordo intersubjetivo, todos os envolvidos encontram-se em igualdade de chances para decidirem as orientações da ação que vão determinar a vida social (Aragão, 1992).

A comunicação pressupõe, aqui, o entendimento mútuo, em que não há possibilidade de coerção, buscando a compreensão. Na interação, o jogo comunicativo acontece, mas não necessariamente no sentido da compreensão - a dominação ou instrumentalização do outro para o sucesso individual também pode acontecer. Peduzzi (1998) coloca que a mediação (interação) tanto pode expressar o agir (ação) comunicativo, quando se busca o entendimento, quanto o agir instrumental, quando se busca atingir um determinado fim ou objetivo. No domicílio e na comunidade, o médico de família entra em contato com um mundo diverso daquele do consultório e pode ter a oportunidade de ampliar seu entendimento da vida cotidiana das pessoas que atende, ao mesmo tempo em que precisa intervir sobre estas pessoas e seus problemas de saúde. 


\section{A comunicação como forma de interação: uma necessidade e possibilidade para a prática médica no contexto da visita domiciliar}

A questão da comunicação é crucial, a nosso ver, para que o encontro entre o médico e o paciente possa realmente acontecer de forma efetiva. Como Scambler e Britten (2001) mencionam, citando Habermas, as "patologias" da comunicação são o resultado da confusão entre as ações orientadas para o entendimento e aquelas orientadas para o sucesso individual. Os médicos tendem a adotar ações estratégicas, com o objetivo de atingirem um determinado objetivo terapêutico, não levando em consideração a opinião do paciente e família, agindo de forma paternalista, com o argumento de que é para o "bem" do outro, trazendo, como consequência, dificuldades em relação ao acompanhamento clínico (Scambler; Britten, 2001).

Segundo Scambler e Britten (2001), os médicos tendem a agir de forma estratégica aberta, procurando atingir as metas propostas no plano terapêutico, podemos assim dizer. O conhecimento leigo, nessa perspectiva, é pouco valorizado. No entanto, os encontros entre o médico e o paciente, muitas vezes, abrangem ações estratégicas veladas que envolvem a manipulação, por um lado, quando o médico utiliza seu conhecimento, ou o jargão médico, para vencer a resistência do paciente, provocando, por assim dizer, um "engano consciente" (conscious deception); mas, por outro lado, envolvendo um "engano inconsciente" (unconscious deception), quando nem o médico e nem o paciente dão-se conta de que agem de forma estratégica, em vez de atuarem de forma comunicativa. Esta é a perspectiva que Scambler e Britten (2001) conceituam de situações onde "a comunicação é sistematicamente distorcida", embora em muitas circunstâncias acreditem agir de forma sincera e por "boa-fé".

Habermas propõe a racionalidade comunicativa da ação.

$\mathrm{Na}$ ação comunicativa os participantes não se orientam primariamente ao próprio êxito; antes perseguem seus fins individuais sob a condição de que seus respectivos planos de ação possam harmonizar-se entre si sobre a base de uma definição compartilhada da situação. Daí que a negociação de definições da situação seja um componente essencial da tarefa interpretativa que a ação comunicativa requer. (Habermas, 1987, p.367, grifo nosso).

A comunicação percebida como entendimento mútuo traz, para a prática clínica desenvolvida na Atenção Primária, novas possibilidades de compreensão do caso e de propostas de solução dos problemas percebidos, uma clínica que possa incluir "possibilidades de prevenção e assistência, incluindo soluções heterodoxas para o manejo de situações já conhecidas" (Ayres, 2008, p.76). O "caso" significa mais do que a condição clínica de um paciente. Ele (o paciente) torna-se "caso" em outro sentido, a partir da compreensão de que o adoecimento tem características singulares em uma biografia e história conhecidas. Pensamos a clínica, como definido por Schraiber (2008), como uma prática entendida como ato, no sentido de ação que realiza o saber médico, e como ele é operado na relação com o paciente e sua família, no contexto da visita domiciliar. Essa clínica tem, no cuidado, a forma característica e processual de operar, inserida na conformação atual da Estratégia Saúde da Família.

Todas as oportunidades de encontro entre o médico e o paciente podem ensejar uma abertura para o diálogo, "um autêntico interesse em ouvir o outro", quando a escuta tem, como horizonte normativo, uma dimensão existencial (Ayres, 2008, p.70-1). As referências passam a ser outras, isto é, aquelas colocadas pelo paciente, e não as restritas aos critérios estabelecidos pelos técnicos. Nesse caso, no encontro, busca-se uma abordagem que alie o êxito técnico com o sucesso prático num horizonte normativo diverso da morfofuncionalidade, é então que pode ocorrer o processo comunicativo (Ayres, 2008). Por êxito técnico, entendemos o "sentido instrumental da ação, por exemplo, a relação entre o uso de um vasodilatador e a redução do risco de danos cardiovasculares num paciente"; por sucesso prático, referimo-nos "ao valor que essa ação assume em relação aos indivíduos e populações, envolvendo as implicações simbólicas, relacionais e materiais dessas ações na vida cotidiana" (Ayres, 2008, p.164). 
Ayres (2008, p.74-5) declara que "não é possível encararmos qualquer relação terapêutica como algo que está começando exatamente ali no momento do primeiro encontro" (entre profissional e usuário). O profissional que surge nesse encontro e, poderíamos dizer também, o usuário, já carregam consigo o modo próprio de como veem o mundo e uma determinada alteridade. Dessa forma, "quando se estabelece uma interação na atenção à saúde não se a inicia; rigorosamente, se a 'retoma'." O autor frisa que, ao se buscar fazer dessa interação um diálogo, abre-se espaço para uma discursividade mais livre, quando a fala dos pacientes não se configura apenas como complementação do discurso do profissional, permitindo "novas possibilidades técnicas e novos sucessos práticos".

Quando ocorre o vínculo entre o médico, o usuário e sua família, pode estabelecer-se o cuidado como uma relação, compartilhando responsabilidades, percebendo qual "projeto de felicidade" interessa àquela pessoa. Ayres (2008) coloca a felicidade não como uma condição material ou espiritual definida a priori, mas como uma ideia reguladora, de natureza contrafática. Isto é, a experiência da felicidade é uma ideia concreta e que "convive todo o tempo com infelicidades: interesses negados, frustrações, obstáculos, limites, dores, angústias. É na negação desses obstáculos que a felicidade vai marcando caminhos para a ação" (p.165).

O aporte habermasiano e as contribuições de Ayres ajudam-nos a perceber quanto a ética comunicativa tem relevância para se refletir sobre o cuidado em saúde, mesmo levando em consideração as dificuldades dessa ética quando confrontada com a assimetria de poder no cuidado em saúde, particularmente do poder médico (Jones, 2001).

No contexto do domicílio, quando o médico visita o paciente e sua família, emergem questões relativas ao cuidado em si, incluindo: os problemas da vida cotidiana, o conhecimento do paciente, da família e do profissional, a experiência adquirida e compartilhada no espaço da visita, entre outras. Isso permite, a nosso ver, um campo fértil para se refletir e investigar a interação médico-paciente e as perspectivas e desdobramentos que levem à construção "de outras formas interativas" (Schraiber, 2008, p.230) mais comunicacionais.

Segundo Schraiber (2008), com a perda histórica da confiança conquistada pela medicina liberal, os dilemas colocados para os médicos surgiram não só no plano da técnica, mas também, e fundamentalmente, no plano da ética. No entanto, se não é mais possível reconquistar a "antiga" confiança perdida no saber, na experiência e na pessoa do médico, o espaço da comunicação e a habilidade em comunicar são imprescindíveis para a construção de uma relação em que a negociação esteja presente.

No entanto, se antigamente os conselhos médicos eram muito valorizados, a tecnologia atual permite, ao paciente, maior acesso à formulação da conduta médica e enseja participação pela disseminação da informação, mas, ao mesmo tempo, restringe o tempo da comunicação. O trabalho de Schraiber $(1997,1993)$ salienta que é esse tempo dedicado à conversa que os médicos buscam preservar, pois representaria a "essência" do caráter liberal de suas práticas. A conversa, necessária, a nosso ver, para que se estabeleça a comunicação é que pode dar sentido diverso à medicina tecnológica. Essa possibilidade está presente na visita domiciliar, no contexto da Estratégia de Saúde da Família.

O objetivo da nossa pesquisa é conhecer como a visita domiciliar pode promover outras formas interativas, favorecendo uma maior comunicação entre o médico, paciente e família, e reorientando a clínica na direção do sucesso prático. Este artigo aborda, particularmente, a percepção dos profissionais e pacientes acerca das potencialidades da visita médica domiciliar.

\section{Metodologia}

Tendo como objeto de pesquisa a visita médica domiciliar, o cenário que vislumbramos é o da Atenção Primária à Saúde (APS), integrada aos princípios e diretrizes básicas do Sistema Único de Saúde (SUS), que inclui a universalidade, equidade e integralidade, seus pilares fundamentais, sendo a ESF, o modelo de organização dos serviços de APS, peculiar do SUS (Andrade et al., 2006; Pustai, 2006). Como o próprio modelo propõe, não é possível uma atuação abrangente que englobe, além 
da assistência curativa, a prevenção e promoção de saúde sem o trabalho de equipe, vínculo e acolhimento, e, neste caso, a presença atuante do agente comunitário de saúde é fundamental.

Nossa pesquisa aconteceu em Florianópolis, capital do estado de Santa Catarina, onde, diferentemente de outras localidades do País, houve a fixação dos médicos na mesma área de abrangência, sendo grande parte com residência ou especialização em Medicina de Família e Comunidade, tendo sido a primeira capital do país a ter cobertura total dos agentes comunitários de saúde, no ano 2000 (Conill, 2002). Além disso, Florianópolis possui uma Rede Docente Assistencial que inclui a maioria dos centros de saúde, onde muitos médicos atuam, também, como supervisores dos graduandos da área da saúde, especialmente do curso de Medicina.

Optamos pela metodologia qualitativa, utilizando as técnicas de observação participante, entrevistas semiestruturadas e leitura de documentos. Essas técnicas dão acesso a uma ampla gama de dados, inclusive àqueles cuja existência o investigador pode não ter previsto no momento em que começou a estudar (Denzin, Lincoln, 2007; Becker, 1993). A pesquisa qualitativa envolve uma abordagem naturalista, interpretativa, e seus pesquisadores procuram entender, ou interpretar, os fenômenos quanto aos significados que as pessoas a eles conferem (Denzin, Lincoln, 2007).

Adotamos os seguintes critérios para escolha dos profissionais que seriam entrevistados, a partir de adaptação baseada em Minayo, Assis e Souza (2005), Minayo (1994), Triviños (1994) e Becker (1993):

- título de especialidade em Medicina de Família e Comunidade ou residência na área;

- antiguidade na comunidade, sendo três anos de atuação no mesmo bairro, e envolvimento com o fenômeno que se quer estudar, associado ao conhecimento amplo e detalhado das circunstâncias que envolvem o foco em análise;

- disponibilidade adequada de tempo para participar no desenrolar das entrevistas e encontros;

- capacidade para expressar, especialmente, o essencial do fenômeno, numa perspectiva de se constituírem em informantes bons e reflexivos.

Com base nesses critérios, a escolha de quais profissionais seriam entrevistados partiu de conversas e informações junto aos coordenadores dos distritos sanitários.

Quanto aos usuários e famílias que seriam entrevistados, a escolha coube ao médico(a) e agentes comunitárias, com a indicação daqueles pacientes que já estavam recebendo acompanhamento da equipe nesse período de três anos, com visitas regulares. Outro critério estabelecido foi o de que o usuário pudesse realizar a entrevista, tendo autonomia para expressão, visto que alguns pacientes visitados pelos profissionais médicos e equipe eram idosos, acamados, com sequelas de doença cerebrovascular, e alguns apresentando dificuldades para falar.

Foram realizadas oito entrevistas com profissionais médicos, dez entrevistas com usuários e familiares, em domicílio, e observadas dez visitas domiciliares realizadas pelos médicos que participaram da pesquisa. Das entrevistas com os profissionais, uma entrevista foi com um médico e seis com médicas de família, contemplando um bairro em cada distrito sanitário. Realizamos, também, uma entrevista com um pediatra, que apoia uma equipe, mas não realiza visita domiciliar. Além disto, observamos o trabalho de supervisão de graduandos de medicina realizado por uma médica de família que também atua na Rede Docente Assistencial, cujos alunos realizam visitas domiciliares. Os usuários e familiares entrevistados por nós não foram os mesmos visitados pelos profissionais médicos, no período de observação de campo realizado. Todas as visitas e entrevistas que realizamos foram intermediadas pelas agentes comunitárias, que nos acompanharam até as casas dos pacientes, sendo que, em algumas situações, presenciaram as entrevistas. Renomeamos os bairros, os nomes dos profissionais e usuários para garantia do sigilo.

Consideramos esse número suficiente e capaz de contemplar as questões colocadas pela pesquisa, pois novas informações substanciais já não eram acrescidas ao material que havíamos coletado (critério de saturação) (Nogueira Martins, Bógus, 2004). Todas as entrevistas foram gravadas e transcritas com o acordo de pacientes e profissionais, e o termo de consentimento livre e informado foi assinado pelos participantes. Adotamos roteiros de entrevistas semiestruturadas com finalidade norteadora, mas dando liberdade para expressão dos entrevistados.

Iniciamos o campo em novembro de 2007, com o pré-teste dos roteiros, prosseguimos nos meses de abril, maio, setembro e outubro de 2008, e complementamos em novembro de 2009, de 
acordo com a disponibilidade dos profissionais e famílias que participaram da pesquisa. A análise e a discussão estiveram presentes nos vários estágios da investigação, sendo o material reavaliado durante todo o processo, na busca de relações e inferências com o quadro conceitual (Nogueira Martins, Bógus, 2004; Triviños, 1994). Exploramos o material coletado visando alcançar os vários núcleos de compreensão, agregando estes dados em categorias teóricas que comandaram a especificação dos temas relacionados à visita médica domiciliar e o encontro do profissional médico com seu paciente neste contexto, objeto do nosso estudo, tendo os aspectos políticos, organizacionais e operacionais como o cenário da prática médica. Essas categorias foram: negociação na visita médica, contribuições da visita médica domiciliar para a prática no consultório; o contexto domiciliar como espaço para interação: a relação com o paciente/família, com a equipe e com os cuidadores; o médico de família e a coordenação do cuidado em saúde.

As entrevistas foram transcritas e lidas diversas vezes, até a impregnação, assim como o caderno de campo. Inicialmente, foram buscadas as categorias utilizadas em cada entrevista, depois, a análise foi realizada por bloco - profissionais, usuários e campo - e, por fim, a triangulação, relacionando o material levantado nas entrevistas, na observação e nas fontes documentais.

\title{
Resultados:
}

\section{a visita domiciliar como instrumento potencializador da interação e comunicação}

Os profissionais médicos afirmam que, na VD, têm a oportunidade de estabelecerem "outro tipo" de atenção e cuidado com o paciente e família. Por estarem no âmbito da Atenção Primária, eles podem e devem ampliar a perspectiva curativa ao implementarem medidas de cunho preventivo, refletindo e incorporando os conhecimentos adquiridos no contato, em domicílio, com os pacientes e famílias que acompanham. Percebemos isso na fala da Dr. ${ }^{a}$ Ester (bairro Beija-Flor):

\begin{abstract}
"A visita é importante porque você sai daquele papel do centro de saúde que é artificial e está indo ali prá ver aquele paciente na sua casa, com a sua cultura, hábitos, que pode ser bom em relação àquela doença ou não. É outra qualidade de atendimento. Como é que está o ambiente? Se há uma ventilação adequada, se há fungos... O idoso prá ver se tem riscos, se tem degrau. Completamente diferente estar na casa do que no consultório".
\end{abstract}

Conhecer a família e cuidar dela, de forma integral, atendendo as crianças, os adultos, os idosos, as gestantes, e tendo a oportunidade de interagir com as pessoas no seu domicílio fortalece o vínculo e pode favorecer a comunicação, o que foi referido tanto pelos pacientes e familiares entrevistados, quanto pelos profissionais. Entretanto, mesmo incorporando uma prática "mais humanizada" e responsável, em geral, o profissional permanece centrado no âmbito de uma prática normativa. Essa conversa não significa, necessariamente, comunicação, pois pode-se cair na armadilha de reduzir essa forma de relação entre o trabalho e interação ao caráter pessoal, exclusivamente, não trazendo reflexos para uma maior autonomia do paciente e família em relação ao cuidado de saúde (Peduzzi, 1998).

Essa abordagem familiar que extrapola o âmbito do diagnóstico e terapêutica de patologias é expressa nesta fala da Dr. ${ }^{a}$ Clara como favorecendo o conhecimento da comunidade e ampliando a satisfação no trabalho:

\footnotetext{
"Aqui é uma comunidade que eu já estou há mais de sete anos trabalhando, conheço todas as pessoas, então, é muito mais prazeroso agora, porque eu conheço bem aquela família que eu estou indo visitar. Conheço bem até por ir visitar, vejo mãe, filho, todo mundo".
}

Na Atenção Primária, com a ESF, a comunicação com os profissionais da equipe torna-se uma necessidade para o desenvolvimento do trabalho em saúde, porque os problemas "de saúde" são abrangentes, envolvem, em geral, questões psicológicas e sociais, exigindo um esforço e a mobilização de saberes e técnicas de várias categorias profissionais. Embora o trabalho em saúde continue 
centralizando-se na figura do médico, fica evidente, a partir da necessidade da prática diária, o questionamento desse modelo (Franco, 2003; Peduzzi, 1998).
"Ela [a visita domiciliar] favorece o trabalho em equipe com a enfermagem. Pode-se discutir sobre aquela família, planejar coisas. Eu faço visita com a enfermeira da minha área. Quando têm muitas visitas, eu faço algumas e ela faz outras. Ela [a visita] abre toda essa visão mais global da saúde. Não envolve só a ausência de doença. Envolve a questão social, a gente acaba se envolvendo em outros aspectos para o tratamento do paciente. Muitas vezes no consultório a gente acha que não deve agir neste aspecto, mas vendo onde a pessoa mora e como

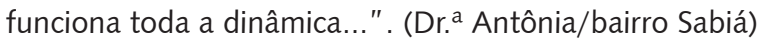

A fala da Dr. ${ }^{a}$ Antônia é significativa ao abordar os problemas de saúde enfrentados pelos pacientes que são percebidos no contexto da Atenção Primária. São problemas que envolvem não apenas o enfrentamento da doença em si, mas também as situações relacionadas que envolvem o contexto social e cultural em que vive a família. Essas questões representam um desafio para toda a equipe de saúde e para o profissional médico, em particular, porque ele se vê imerso num contexto em que a medicina tecnológica, em geral, tem pouco para ofertar-lhe. Ele necessita do aporte de novos conhecimentos e do auxílio de outros profissionais. E, além disso, o profissional médico precisa lidar com os seus próprios limites, admitindo que as alternativas e encaminhamentos para os problemas passam, necessariamente, pela participação do usuário e sua família.

Algumas vezes, como observamos e nos foi relatado, problemas sociais relacionados com a pobreza e a violência, como o tráfico de drogas, eram vistos como motivo do problema de saúde do paciente, como a hipertensão arterial e a depressão, e mobilizavam a equipe de saúde. No entanto, os encaminhamentos realizados restringiam-se ao escopo das ações voltadas às patologias do paciente, não conseguindo, a equipe, elaborar planos de enfrentamento mais abrangentes e intersetoriais, de forma conjunta com o paciente e família. Exemplo disso foi a situação de uma senhora cujos filhos se envolveram com o tráfico de drogas, no bairro Sabiá. A equipe procurou apoiar e estimular a paciente para o enfrentamento dos problemas, visitando-a, levando-a também à psicóloga, agendando horário de consulta, no centro de saúde, compatível com a folga de uma das filhas, para que ela pudesse acompanhar a mãe. No entanto, o apoio ao filho acabou sendo oferecido pela igreja evangélica, que a família passou a frequentar.

Ao deslocar o médico do consultório, no centro de saúde, e integrá-lo à equipe, tendo como ponto de partida os problemas das pessoas atendidas na sua área de abrangência, a interação propicia que a comunicação aconteça na prática diária. Dr. Cláudio (bairro Bem-Te-Vi) narra sua percepção de como "a conversa" muda quando visita a casa do paciente.

\footnotetext{
“Identificar que o paciente não é só aquela pessoa que está no consultório, mas dentro do trabalho, dentro da casa, influencia mais do que uma conversa de poucos minutos dentro daquela sala que é o consultório. Muitas vezes, no consultório, por falta de tempo ou por excesso de demanda, o foco da conversa é em cima da patologia, em cima do exame, em cima da prescrição. [...]

Eu fico mais à vontade com as famílias que eu faço VD. Cria mais amizade e essa amizade facilita a terapêutica. A credibilidade até mesmo pra abrir as nossas fraquezas, as nossas carências, falar assim: Olha, eu não vou conseguir ajudar o senhor, prá esse problema. Essa abertura fica muito mais sincera com o paciente que tu tens esse contato pela VD. Algumas vezes acontece no consultório, mas a VD favorece muito mais que aconteça isso". (Grifo nosso).
}

A interação é percebida, pelo Dr. Cláudio, como amizade. Essa interação, gerando a possibilidade de autenticidade - pressuposto para a comunicação - fica mais evidente no domicílio. Isso porque, por um lado, pela relação mais intimista que a VD favorece, e, por outro lado, pelo contraste com o "clima" mais técnico presente no consultório, onde o profissional médico representa a autoridade e 
onde a impessoalidade, atributo de uma medicina tecnológica, é dominante. Este é o sentido do que menciona a Dr. ${ }^{a}$ Lígia, quando os pacientes a tratam "como se fosse da família". Os médicos falam da interação e da afetividade que existe na relação com os pacientes e familiares que acompanham como algo inusitado e surpreendente, o que chama a atenção, já que deveria fazer parte da prática diária do médico, considerando especialmente o contexto da Atenção Primária. Ao refletirmos sobre o contexto de despersonalização presente na medicina tecnológica, a fala dos profissionais expressa uma justificação para esse tipo de relação-médico paciente que se torna "mais pessoal" e pode, inclusive, ser percebida como "menos profissional".

Esse fato é revelador na fala do Dr. Cláudio, quando associa a sinceridade necessária na relação com o paciente - sendo claro quanto aos próprios limites - a um sinal de fraqueza. O contexto do domicílio pressupõe condições e situações que expõem o médico, que perde um pouco da "majestade" que tem no consultório, ficando, poderíamos assim dizer, mais humano, porque menos onipotente. Da perspectiva dos pacientes, há uma "humanização" do profissional, que passa a ser visto também como "pessoa", além de médico.
“Eu me sinto muito bem, eu fico feliz quando ela [Dr. ${ }^{a}$ Lígia] vem. Ela é uma pessoa muito especial. Eu gosto muito da visita dela e da visita de vocês [olha para mim e para as agentes]. Eu gosto da visita dela não é porque ela é médica, mas porque é uma pessoa muito dedicada. Ela cuida bem da gente, ela é uma pessoa legal, é médica e é uma pessoa muito legal". (Terezinha/bairro Canário, grifo nosso)

Na observação de campo, percebemos que Dr. ${ }^{a}$ Lígia, ao reforçar a importância dos protocolos frente às condutas terapêuticas instituídas, procurava justificar sua forma de atuar, como se pudesse estar incorrendo em erro ao compartilhar de percepções e opiniões dos pacientes e familiares e relativizar as normas estabelecidas pela técnica no sentido de melhor cuidar de seus pacientes. No entanto, por estar na casa do usuário, o profissional médico tem maior possibilidade de compreender os problemas e "negociar" determinada conduta. Ao conhecer a realidade de vida daquele usuário e família, suas dificuldades e conhecimentos, é possível compartilhar com ele e com a família o cuidado a ser realizado.

\footnotetext{
"Lembro de algumas visitas que eles reclamavam porque eu não levava receituário. Muitas vezes eu sabia que tinha familiares e cuidadores que podiam pegar a receita aqui na unidade de saúde. Então eu fazia a VD sem receituário, justamente pra sentar, conversar e fazer essa discussão. Essa discussão sobre a conduta, da medicação ou sobre o estilo de vida, o que seja, foi uma coisa que eu trouxe pro consultório em função da VD. Na faculdade a gente aprendia tanta coisa pra orientar e o paciente não fazia. Ou porque não tinha possibilidade, ou porque era impossibilitado por alguma coisa dentro de casa. Ao fazer a VD, acho que talvez tenha trazido mais essa discussão. Se o paciente pode ou não pode fazer algumas coisas". (Dr. Cláudio/Bem-Te-Vi)
}

Aqui a VD, ao "aproximar" o médico do contexto de vida do paciente e da família, possibilita uma articulação entre as ações que são estratégicas e que buscam o êxito técnico, com negociações advindas de uma interação mais voltada à comunicação e que se relacionariam ao sucesso prático.

\footnotetext{
"Lembro de um caso de um senhor que me agradeceu o máximo, no dia em que eu falei pra ele que podia comer uma picanha uma vez por mês. Fazia três anos que ele não comia carne com gordura nenhuma. O sonho dele era voltar a comer picanha. Ele tinha 89 anos, gaúcho... Chorou e me abraçou quando eu disse que podia comer picanha. Essa combinação eu fiz numa VD". (Dr. Cláudio/Bem-Te-Vi)
}

Para o Dr. Cláudio, ele conseguiu "negociar" com o paciente uma maneira menos penosa de lidar com a dieta (e, de fato, pode ter conseguido). No entanto, esta é uma atitude de "engano inconsciente", pois a opção de comer ou não picanha, ou quantas vezes, poderia ter sido decidida pelo paciente, 
considerando, este, os problemas relacionados e as consequências de uma dieta plena de gordura saturada, o que não foi devidamente esclarecido pelo médico, mesmo que tivesse "boa intenção".

Outras situações observadas sugerem que os médicos, embora mencionem que procuram seguir os critérios e protocolos técnicos de tratamento, contemporizam as condutas quando no domicílio, confrontados com as opiniões dos pacientes. Um exemplo disso foi observado quando da visita de Dr. ${ }^{a}$ Clara a uma paciente hipertensa, que relutava em tomar a medicação "por não sentir nada". A paciente relatou seu desejo de retornar para o seu estado de origem, mas estaria impedida no momento em função dos cuidados de saúde, precisando morar com a filha em Florianópolis. Dr. ${ }^{a}$ Clara, no entanto, não abordou o assunto, focalizou o problema da pressão arterial. Ao perceber a resistência da paciente em usar medicação, orientou sobre caminhadas até o centro de saúde, situado nas proximidades da residência da família, quando a paciente poderia tomar sol, verificando sua pressão. Reforçou orientações sobre a dieta, conversando também com a filha da paciente que estava presente na visita. A prescrição da medicação não foi feita. A médica declarou, posteriormente, acreditar que a paciente possa ser "convencida" a iniciar a medicação e preferiu, naquele momento, enfatizar as medidas viáveis para a paciente realizar. Podemos perceber aqui o dilema da profissional. Embora "percebendo" que o problema mais importante para a paciente estava relacionado com sua permanência na cidade e seu desejo em regressar para sua cidade de origem, a médica agiu com "engano consciente". Procurou centralizar sua ação no diagnóstico da hipertensão arterial e no melhor "convencimento" da paciente, o que não significa que não fosse tecnicamente necessário, mas que ficava aquém do desejo da usuária.

Dr. ${ }^{a}$ Lígia, por sua vez, tem acompanhado uma senhora hipertensa que faz uso de medicação e que vem apresentando um aumento da glicemia. Ela e a filha relataram que a médica solicitou que procurasse se cuidar, fazendo dieta e exercícios para evitar tomar outra medicação. A paciente relatou, ainda, que sua pressão sobe, sobretudo, quando fica nervosa, inclusive quando vai ao centro de saúde. No domicílio, sua pressão arterial se normaliza com a medicação. Por isso, a médica mantém o mesmo esquema terapêutico. Neste caso, não nos pareceu que a paciente e sua filha estivessem a par do que acontecia. Pelo que foi descrito pela paciente, a mesma apresentava a típica "síndrome do jaleco branco", quando o paciente tem sua pressão arterial elevada ao se deparar com um profissional de saúde, em função da ansiedade. Embora a médica tenha percebido a situação, ela não esclareceu o fato para a paciente e sua filha, segundo nossa observação.

A interação entre o profissional médico e o paciente e sua família, na VD, propicia que um maior entendimento mútuo leve a ações de saúde que busquem aliar êxito técnico e sucesso prático. No entanto, esta interação varia, pois os profissionais médicos têm posicionamentos diversificados entre si. As reflexões aqui expostas indicam que a VD realizada pelo médico pode representar um dispositivo que inicia um questionamento dos pressupostos da medicina tecnológica. Isto pode acontecer quando a finalidade última das ações de saúde não fique restrita ao êxito técnico, mas que articule a elas, mediante possibilidades abertas pela comunicação, os projetos dos usuários e pacientes, as ações de promoção e prevenção e os problemas da comunidade. (Ayres, 2008). A VD possibilita este espaço interativo em que a comunicação e a negociação em relação ao diagnóstico e o cuidado realizado podem ocorrer.

\section{Considerações finais}

Esses encontros entre o profissional médico e o paciente permitem que retomemos algumas considerações já realizadas, seguindo as formulações de Schraiber (2008). Na Atenção Primária, a ESF possibilitou que o médico de família, ao encontrar o paciente no contexto da comunidade onde vive, e também local de trabalho da equipe de saúde, fortalecesse o vínculo, gerando uma relação de maior confiança. Esse fato propicia o desenvolvimento de uma relação não apenas baseada no caráter técnico da prática, mas também inclui relações mais comunicativas.

A proximidade, a possibilidade de conversar sem ter pressa de atender outro paciente que aguarda a consulta, de encontrar familiares, observar, sentir e presenciar um pouco da vida daquela família 
faz diferença para o médico e para o paciente. Essa proximidade, o reconhecimento das dificuldades pelas quais passam os pacientes e familiares permitiriam, ao profissional, buscar alternativas para $o$ acompanhamento clínico que leve em consideração os desejos dos usuários, concorrendo, assim, para o sucesso prático.

A visita médica é uma atividade em que o profissional médico tem a oportunidade de sair do seu casulo, o consultório. De posse dos protocolos e diretrizes clínicas, que são genéricos e estabelecidos para coletivos, o profissional vai deparar-se com o conhecimento, a cultura e os meios disponíveis por paciente e sua família, na sua casa. Essa situação, como vimos, tem um "potencial de realidade" que suscita que o profissional procure desenvolver o trabalho em equipe, articulado às outras especialidades, e intersetorial, uma vez que, para lidar com os problemas de saúde de forma abrangente, é necessário o aporte de conhecimentos e cuidados dos outros profissionais.

Assim, embora tenha objetivos práticos com metas terapêuticas que "deve" perseguir para que os pacientes apresentem melhora clínica, o plano terapêutico desenvolvido "com os pacientes" no domicílio, especificamente falando, vai modificando-se conforme o tempo e é diferente do plano "para os pacientes". O diagnóstico, a adesão e o tipo de tratamento levam em conta aquilo que o paciente e a família necessitam e podem fazer, levando em consideração as dificuldades que encontram no dia a dia, no lidar com o problema de saúde.

Como mencionou um dos profissionais entrevistados, a VD permite que o médico possa também expressar os seus limites, admitindo que não tem todas as respostas, e, por vezes, precisa estudar mais, discutir com a equipe ou encaminhar para um especialista.. Entretanto, precisamos deixar claro as limitações decorrentes da metodologia utilizada, já que estudou-se a ESF em uma localidade bastante particular, com alto grau de fixação e formação dos profissionais na especialidade, e uma condição social bem melhor que o conjunto do país. De toda a forma, pelo desenho do estudo, estes dados não são, de forma alguma, generalizáveis para outras localidades, e servem como instigador da discussão das potencialidades e limites da estratégia.

A Atenção Primária e os profissionais nela inseridos precisam buscar, além da eficácia técnica, a compreensão das necessidades surgidas na dinâmica da vida das pessoas e famílias que atendem. Essas necessidades vão além do estabelecido pela biomedicina, fazem parte da vida e, sobretudo, do adoecimento das pessoas. Assim, ao fazer a VD, o profissional médico tem a oportunidade de percebê-las de forma diferenciada. Elas trazem questões éticas que desafiam às equipes de saúde, ensejando respostas a serem buscadas de forma compartilhada e com caráter intersetorial. Ao buscar a comunicação num processo interativo que se baseie no entendimento mútuo, o profissional médico tem, diante de si, o desafio de deixar de aplicar o rigor dos manuais técnicos para compartilhar um cuidado no qual o paciente e a família colocam os seus limites e os seus projetos.

\section{Colaboradores}

Renata Borges elaborou o problema da pesquisa, realizou o trabalho de campo e redigiu o artigo. Ana Flávia Pires Lucas D Oliveira foi responsável pela revisão da versão final do manuscrito.

\section{Referências}

ANDRADE, L.O.M. et al. Estratégia Saúde da Família. In: DUNCAN, B.B. et al. (Orgs.). Medicina ambulatorial: condutas de atenção primária baseadas em evidências. São Paulo: Artmed, 2006. p.88-100.

ALBUQUERQUE, A.B.B.; BOSI, M.L.M. Visita domiciliar no âmbito da Estratégia Saúde da Família: percepções de usuários, município de Fortaleza, Ceará, Brasil. Cad. Saude Publica, v.25, n.5, p.1103-12, 2009. Disponível em: <http://www.scielosp.org/pdf/csp/ v25n5/17.pdf>. Acesso em: 12 jan. 2010. 
ARAGÃO, L.M.C. Razão comunicativa e teoria social crítica em Jürgen Habermas. Rio de Janeiro: Tempo Brasileiro, 1992.

AYRES, J.R.C.M. Para comprender el sentido práctico de las acciones de salud: contribuciones de la hermenêutica filosófica. Salud Colect., v.4, n.2, p.159-72, 2008.

BECKER, H.S. Métodos de pesquisa em Ciências Sociais. São Paulo: Hucitec, 1993

BERG, $M$. J. et al. Changing patterns of home visiting in general practice: an analysis of electronic medical records. BMC Fam. Pract., v.7, n.58, 2006. Disponível em: <http://www.biomedcentral.com/1471-2296/7/58>. Acesso em: 10 out. 2009.

BERGERON, R. et al. Which physicians make home visits and why? A survey. Canadian Med. Assoc. J., v.161, n.4, p.369-73, 1999. Disponível em: <http://www.ncbi.nlm.nih. gov/pmc/articles/PMC1230536/> . Acesso em: 20 dez. 2009.

BORGES, R. Visita médica domiciliar: espaço para interação, comunicação e prática estudo de caso no Programa Saúde da Família, município de Florianópolis, Santa Catarina. 2010. Tese (Doutorado) - Programa de Medicina Preventiva, Faculdade de Medicina, Universidade de São Paulo, São Paulo. 2010.

CONILL, E.M. Políticas de atenção primária e reformas sanitárias: discutindo a avaliação a partir da análise do Programa Saúde da Família em Florianópolis, Santa Catarina, Brasil, 1994-2000. Cad. Saude Publica, v.18, supl., p.191-202, 2002.

CUNHA, G.T. A construção da clínica ampliada na Atenção Básica. São Paulo: Hucitec, 2005

DALMASO, A.S.W. Análise de transformações da técnica em Medicina: reflexões sobre uma proposta metodológica. Interface - Comunic., Saude, Educ., v.4, n.6, p.49-60, 2000 .

DENZIN, N.K.; LINCOLN, Y.S. O planejamento da pesquisa qualitativa: teorias e abordagens. São Paulo: Artmed/Bookman, 2007

FRANCO, T.B.; MERHY, E.E. Programa de Saúde da Família (PSF): contradições de um programa destinado à mudança do modelo tecnoassistencial. In: MERHY, E. E. et al. (Orgs.). O trabalho em saúde: olhando e experienciando o SUS no cotidiano. São Paulo: Hucitec, 2003. p.55-124.

HABERMAS, J. Teoria de la acción comunicativa. Madri: Taurus, 1987.

JONES, I.R. Health care decision making and the politics of health. In: SCAMBLER, G. (Ed.). Habermas, critical theory and health. London: Routledge, 2001. p.68-85.

JOYCE, C.; PITERMAN, L. Trends in GP home visits. Austr. Fam. Physician, v.37, n.12, p.1039-42, 2008. Disponível em: <http://www.racgp.org.au/afp/200812/29330> Acesso em: 10 out. 2009.

MCWHINNEY, I.R. A textbook of family medicine. New York: Oxford University Press, 1997

MINAYO, M.C.S. O desafio do conhecimento: pesquisa qualitativa. São Paulo: Hucitec, 1994

MINAYO, M.C.S.; ASSIS, S.G.; SOUZA, E.R. (Orgs.). Avaliação por triangulação de métodos: abordagem de programas sociais. Rio de Janeiro: Fiocruz, 2005.

NOGUEIRA MARTINS, M.C.F.; BÓGUS, C.M. Considerações sobre a metodologia qualitativa como recurso para o estudo das ações de humanização em saúde. Saude Soc. v.13, n.3, p.44-57, 2004.

PEDUZZI, M. Equipe multiprofissional de saúde: a interface entre trabalho e interação. 1998. Tese (Doutorado) - Programa de Pós-Graduação em Saúde Coletiva, Departamento de Medicina Preventiva e Social, Faculdade de Ciências Médicas, Universidade Estadual de Campinas. 1998. 
PERES, E.M.; DAL POZ, M.; GRANDE, N.R. Visita domiciliar: espaço privilegiado para diálogo e produção de saberes. Rev. Enferm. UERJ, v.14, n.2, p.208-13, 2006.

PUSTAI, O.J. O Sistema de Saúde no Brasil. In: DUNCAN, B.B. et al. (Orgs.). Medicina ambulatorial: condutas de atenção primária baseadas em evidências. São Paulo: Artmed, 2006. p.69-75.

SCAMBLER, G.; BRITTEN, N. System, lifeworld and doctor-patient interaction: issues of trust in a changing world. In: SCAMBLER, G. (Ed.). Habermas, critical theory and health. London: Routledge, 2001. p.45-67.

SCHRAIBER, L.B. O médico e seu trabalho: limites da liberdade. São Paulo: Hucitec, 1993.

Medicina tecnológica e prática profissional contemporânea: novos desafios, outros dilemas. 1997. Tese (Livre Docência) - Faculdade de Medicina, Universidade de São Paulo, São Paulo.

O médico e suas interações: a crise dos vínculos de confiança. São Paulo: $\overline{\text { Hucitec }}, 2008$.

STARFIELD, B. Is primary care essential? Lancet, v.344, n.8930, p.1129-33, 1994. Disponível em: <http://www.sbmfc.org.br/media/file/artigos/isprimarycare.pdf>. Acesso em: 14 dez. 2009.

TAKEDA, S. A organização de serviços de Atenção Primária à Saúde. In: DUNCAN, B. B. et al. (Orgs.). Medicina ambulatorial: condutas de Atenção Primária baseadas em evidências. São Paulo: Artmed, 2006. p.76-87.

TRIVIÑOS, A.N.S. Introdução à pesquisa em Ciências Sociais: a pesquisa qualitativa em educação - o Positivismo, a Fenomenologia, o Marxismo. São Paulo: Atlas, 1994.

VIANA, A.L.D.; DAL POZ, M.R. A reforma do Sistema de Saúde no Brasil e o Programa de Saúde da Família. Physis, v.8, n.2, p.11-48, 1998.

BORGES, R.; D'OLIVEIRA, A.F.P.L. La visita médica domiciliaria como espacio para interacción y comunicación en Florianópolis, estado de Santa Catarina, Brasil. Interface Comunic., Saude, Educ., v.15, n.37, p.461-72, abr./jun. 2011.

Este artículo discute la visita médica domiciliaria sobre la base de una investigación efectuada en la municipalidad de Florianópolis, teniendo como escenario a la Estrategia Salud de la Familia. El objetivo principal fue entender como la visita domiciliaria impacta la práctica médica, enfocando cambios en la calidad de la interacción entre el profesional, el paciente y su familia. Fue adoptada la metodología cualitativa, con triangulación de técnicas, combinando entrevistas, observación participante y lectura de documentos. Se observó que la visita domiciliaria fomenta la interacción por promover una comunicación dirigida al entendimiento mutuo, lo que facilita la composición profesional de conductas que buscan la eficacia técnica (éxito técnico) con el entendimiento y se centran en proyectos de felicidad de los pacientes y familiares (éxito en la práctica).

Palabras clave: Visita médica domiciliaria. Comunicación. Interacción. Estrategia Salud de la Familia.

Recebido em 16/05/2010. Aprovado em 28/10/2010. 